$24.1 \mid 2020$

Varia

\title{
Le duc de Bourgogne et son reliquaire de Liège (1467-1471)
}

\section{Philippe George}

\section{(2) OpenEdition}

Journals

Édition électronique

URL : https://journals.openedition.org/cem/17193

DOI : $10.4000 /$ cem. 17193

ISSN : 1954-3093

Éditeur

Centre d'études médiévales Saint-Germain d'Auxerre

Référence électronique

Philippe George, «Le duc de Bourgogne et son reliquaire de Liège (1467-1471) », Bulletin du centre d'études médiévales d'Auxerre | BUCEMA [En ligne], 24.1 | 2020, mis en ligne le 21 septembre 2020, consulté le 22 septembre 2022. URL : http://journals.openedition.org/cem/17193 ; DOI : https:// doi.org/10.4000/cem. 17193

Ce document a été généré automatiquement le 22 septembre 2022.

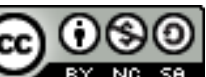

Creative Commons - Attribution - Pas d'Utilisation Commerciale - Partage dans les Mêmes Conditions 4.0 International - CC BY-NC-SA 4.0

https://creativecommons.org/licenses/by-nc-sa/4.0/ 


\section{Le duc de Bourgogne et son reliquaire de Liège (1467-1471)*}

\section{Philippe George}

«a Gerart Loyet, orfevre de mondit seigneur, sur ce qu'il lui porroit estre deu a cause de certain ymage d'or, que icellui seigneur lui avoit ordonné de faire, pour le presenter a monseigneur Saint Lambert de Liege, XII ${ }^{c}$ livres [...]»: c'est en ces termes qu'est mentionné, pour la première fois, en 1467 , le reliquaire dit de Charles le Téméraire dans le relevé des dépenses consenties par le tout-puissant prince de Bourgogne pour la réalisation de cette prestigieuse orfèvrerie offerte à Liège ${ }^{1}$. C'est en 1883 que l'historien de l'art Jules Helbig, véritable pionnier, opère, le premier, le rapprochement entre l'œuvre d'art conservée au Trésor de la Cathédrale de Liège et l'orfèvreconcepteur Gérard Loyet (fig. 1) ${ }^{2}$.

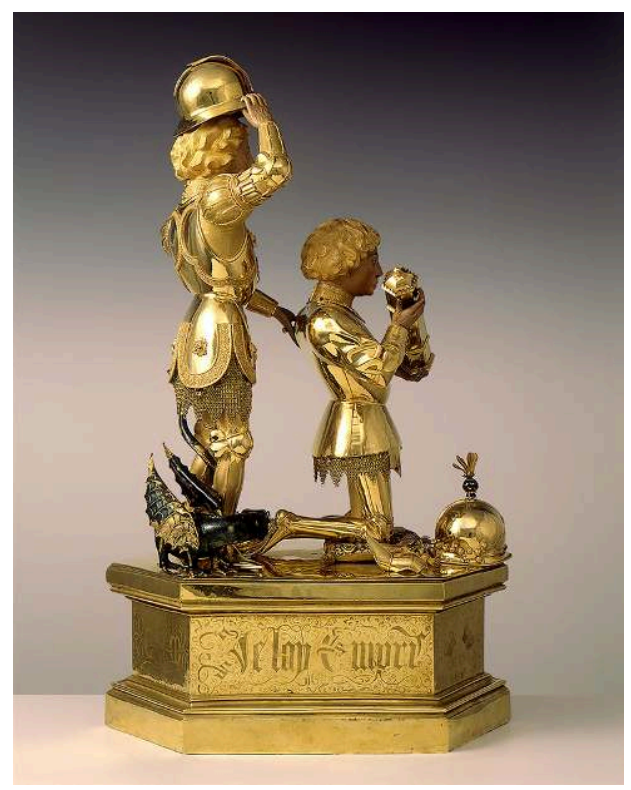


Fig. 1 - Reliquaire de Charles le Téméraire, Trésor de Liège

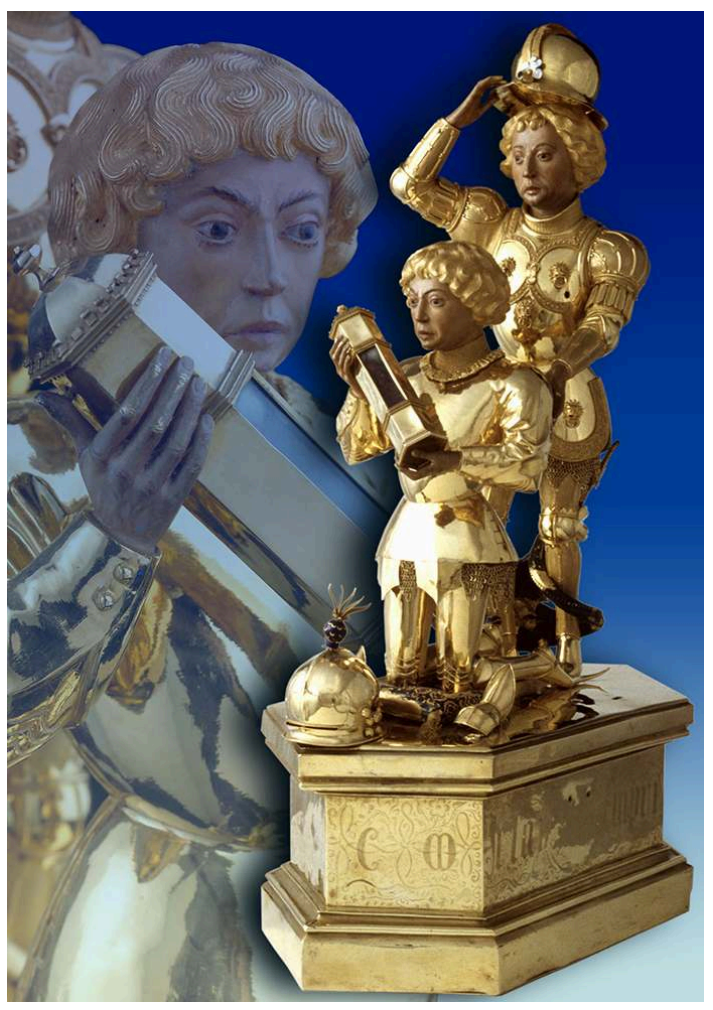

(c) Liège, Hubert Gérin

2 L'art et l'histoire se conjuguent dans ce précieux objet qui s'inscrit au sein d'un long et lourd conflit entre Liège et Bourgogne au $\mathrm{xV}^{\mathrm{e}}$ siècle : la principauté de Liège constituait en effet un écueil de résistance en plein milieu des territoires rassemblés sous le pouvoir bourguignon, dans leurs « pays de par-deçà » ${ }^{3}$.

Sur un haut socle oblong de forme hexagonale sont fixées deux statuettes orfévrées ${ }^{4}$ : Charles le Téméraire, à genoux, présenté par saint Georges, debout. Sur la face longue du socle apparaît, de part et d'autre, la devise du Téméraire : « JE LAY EMPRI (N) S », c'està-dire «Je l'ai entrepris $»^{5}$. Sur l'une des faces, le texte de la devise est scindé entre l'auxiliaire et le participe passé pour laisser place à un écu des armoiries du duc ${ }^{6}$, disparu - et aujourd'hui refait (fig. 2). 
Fig. 2 - Reliquaire de Charles le Téméraire, Trésor de Liège

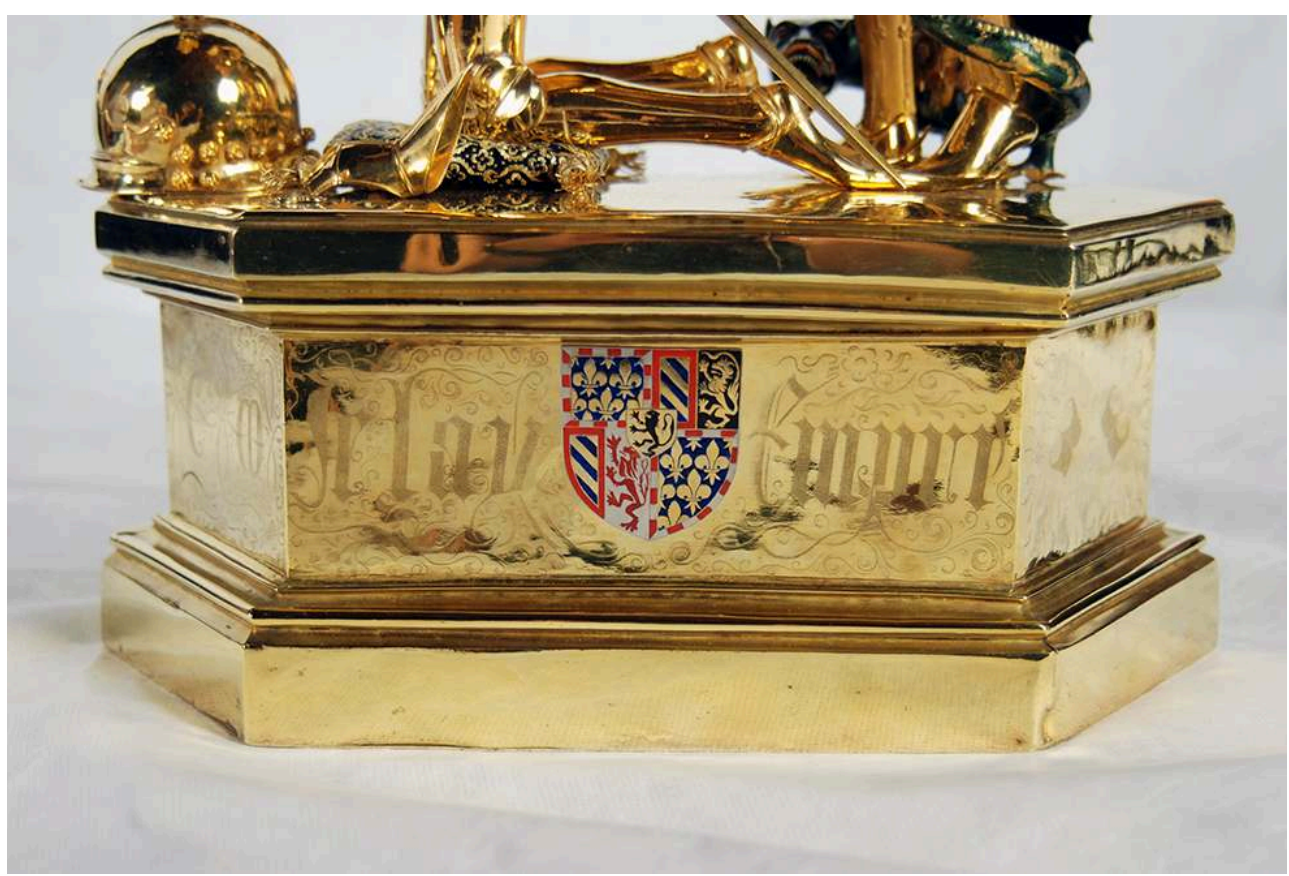

(c) Vienne, Kunsthistorisches Museum

4 Sur les deux faces avant du socle hexagonal, un « $\mathrm{C}$ » et un « $\mathrm{M}$ » sont réunis par des fleurs et des lacs d'amour, initiales de Charles et de sa troisième épouse Marguerite $d^{\prime} Y{ }^{7}{ }^{7}$; les deux flancs arrière s'ornent des flammes et des briquets de Bourgogne. Ces inscriptions et décorations sont un remarquable travail d'orfèvrerie de gravure au pointillés d'une "subtilité arachéenne »".

5 Charles est à genoux sur un coussin couvert d'émail translucide d'un bleu profond, bien diapré d'or, et dont les glands sont tressés en fil d'or. Le duc tient en mains un réceptacle hexagonal, une face vitrée en son milieu d'une fenêtre en cristal de roche, qui laisse deviner la présence d'une relique soigneusement enveloppée de soie rouge. En 2001, au retour de l'exposition de Beaune, nous y avons découvert le troisième métacarpien d'une main droite, dont l'épiphyse proximale est en partie détruite. Il est accompagné d'une authentique sur parchemin $(24 \times 7 \mathrm{~mm})$, collée sur un papier, d'une écriture $\mathrm{du} \mathrm{Xv}^{\mathrm{e}}$ siècle (?) à l'encre rouge, difficilement lisible et retranscrite au $\mathrm{XIX}^{\mathrm{e}}$ siècle sur un papier, avec l'inscription : Digitus S(ancti) Lambert $(i)^{10}$.

\section{Especial reliance : la dévotion obsessionnelle d'un prince?}

6 Nous partageons entièrement les vues d'Hugo van der Velden lorsqu'il démontre que le reliquaire tenu en mains par Charles est originel. Maintes occasions furent offertes au duc d'acquérir une relique de saint Lambert. Rappelons qu'après sa victoire de Brustem sur les Liégeois, le nouveau duc entre en vainqueur à Liège le 17 novembre 1467 et visite la cathédrale; la dépense à Loyet date de décembre 1467. Mais les hostilités reprennent: elles conduiront au funeste sac de Liège par les Bourguignons dès le 3 novembre 1468. Dans la cathédrale Saint-Lambert, au dire des chroniqueurs, Charles a pourtant pris lui-même la défense de la châsse du saint patron. Le cadeau d'une relique 
comme remerciement de la part des chanoines n'aurait rien d'étonnant qu'on sait que son lieutenant Guy de Brimeu, seigneur d'Humbercourt, obtiendra pareil présent pour lui-même ${ }^{11}$. On sait en effet qu'en 1468 Humbercourt fit mettre en sécurité la châsse du saint, qu'il obtint des reliques ${ }^{12}$, qu'en 1472 il participa au projet d'un buste-reliquaire pour renfermer la tête du saint ad instar capitis sancti Servatii à Maastricht ${ }^{13}$, et qu'il donna même le prénom Lamberte à l'une de ses filles. Le don par le duc à la cathédrale de Liège de somptueux ornements liturgiques décorés de scènes de la vie de saint Lambert et la fondation d'une messe hebdomadaire au même moment peuvent être mis en relation avec le cadeau insigne du reliquaire, mais sans certitude ${ }^{14}$. Cela forme en tout cas un bel ensemble en faveur du grand saint liégeois, qui pourrait aussi s'inscrire dans un élan de restitution du butin prélevé sur les églises du pays en 1468, élan encouragé par le pape ${ }^{15}$. L'identification de la relique avec une relique de saint Lambert remonte à l'ouvrage de Jean Chapeauville de 1616, le "père de l'historiographie moderne liégeoise ${ }^{16}$. Déjà en 1610 on sait que le Téméraire tient en mains «quelques saintes reliques ${ }^{17}$. Il faut attendre 1616 pour trouver la précision qu'il s'agit de saint Lambert ${ }^{18}$. Enfin pour l'identification précise d'un doigt, serait-ce le chanoine Thimister le premier à en parler dans la première édition de son Histoire de Saint-Paul en $1867^{19}$ ? Ce retard d'identification ne peut-il par ailleurs s'expliquer?

\section{Mauvaise conscience, repentance, résilience ou reconnaissance?}

7 Nous sommes fascinés par cette œuvre maîtresse du Trésor de la Cathédrale de Liège et du patrimoine international. C'est une histoire de plus de quarante ans que nous avons vécue ex officio à ses côtés, depuis son départ en 1980 pour l'exposition au Victoria and Albert Museum jusqu'aux expositions, après 2000, de Beaune ${ }^{20}$ et de la triade Berne/ Vienne/Bruges, consacrée au Téméraire ${ }^{21}$. Il nous a paru utile de rassembler ici les éléments neufs découverts depuis l'ouvrage de Hugo van der Velden, depuis notre article des Annales de Bourgogne et notre communication au colloque de Berne en $2012^{22}$. Conjointement, nous avancerons de nouvelles hypothèses. La multiplicité des questions que suscite ce groupe orfévré et la bibliographie exponentielle de l'histoire bourguignonne, dans un dossier interdisciplinaire très complexe, n'ont d'égal que l'engouement sans cesse croissant d'un large public pour le « siècle de Bourgogne ${ }^{23}$.

8 Les expositions vont être l'occasion d'un intérêt plus soutenu encore pour le reliquaire de Charles le Téméraire, qui progressivement s'impose comme une, sinon comme la carte de visite du patrimoine artistique de Liège. N'est-il pas paradoxal de constater que c'est précisément à Liège, dans la ville qu'il a mise à sac en 1468, que Charles conserve aujourd'hui sa plus belle représentation? En 1960, pour l'exposition de Bruges/Détroit, Paul Coremans, premier directeur de l'Institut royal du patrimoine artistique, formulait quelques hypothèses intéressantes ${ }^{24}$. En empruntant l'œuvre pour le Victoria and Albert Museum en 1980, Claude Blair et Marian Campbell entament une réflexion de fond sur le dossier. Ils reconstituent le contexte historique et artistique de l'époque et suggèrent même que le reliquaire dans les mains du duc n'est pas, à leurs yeux, l'objet originel qu'il tenait, mais qu'il faut plutôt imaginer une épée ou les clés de la ville de Liège, voire une réduction du fameux perron ${ }^{25}$. Ils sont les premiers à parler d'ex-voto ${ }^{26}$. Hugo van der Velden va pousser l'enquête beaucoup plus loin. 
9 Il ne fait pas de doute que la pièce qui est appelée, depuis longtemps, pour toujours sans doute et indûment, « le reliquaire de Charles le Téméraire » du Trésor de Liège est en fait un ex-voto à Monseigneur saint Lambert ${ }^{27}$. Commandée à Gérard Loyet par Charles et offerte au saint patron de la cathédrale de Liège, l'œuvre a été réalisée entre 1467 et 1471 .

10 Décembre 1467, d'abord, est la date de la dépense. 1468, ensuite, le 3 juillet, c'est le mariage, de Charles le Téméraire avec Marguerite d'York, dont la mémoire est perpétuée par les initiales « $C$ » et « $M$ » inscrites sur le reliquaire. 1471, enfin, le 14 février, l'œuvre est mentionnée pour la première fois à la cathédrale de Liège dans les chroniques contemporaines de Jean de Looz et d'Adrien d'Oudenbosch ${ }^{28}$. Depuis le moment de sa commande, l'œuvre a évolué dans sa réalisation en fonction de l'actualité29. Outre la victoire du duc sur les Liégeois à Brustem le 28 octobre 1467, une autre circonstance importante est à prendre en considération en cette année $1467:$ la visite de Charles à la cathédrale Saint-Lambert. À cette occasion, le prince fait un don d'argent pour lui avoir exposé les reliques du saint patron ${ }^{30}$.

11 À l'analyse de plusieurs spécialistes ${ }^{31}$, le «reliquaire » est atypique. Bien sûr les iconographies de donateurs tenant en mains des reliques sont plutôt rares, mais la singularité de l'œuvre réside, à notre avis, ailleurs. Il est inouï qu'une œuvre de cette valeur ait survécu jusqu'à nous. Des dégâts survinrent toutefois, auxquels le XIX siècle apporta restauration.

\section{L'inquiétant regard du Téméraire}

12 Les carnations des visages et des mains des statuettes ont été peintes au naturel au $\mathrm{XVIII}^{\mathrm{e}}$ siècle et rafraîchies au XIX ${ }^{\mathrm{e}}$ siècle, ce qui donne de grands yeux, plus à Charles qu'à saint Georges, et accentue son regard par des sourcils et des cils inférieurs plus fortement marqués.

13 Les portraits du grand-duc d'Occident se rencontrent à la fois dans les enluminures, sur des panneaux peints, mais aussi sur des médailles. Le portrait du Téméraire sur le reliquaire de Liège se distingue doublement : c'est la seule représentation d'orfèvrerie conservée et elle interpelle par son mimétisme avec celle de saint Georges ${ }^{32}$. D'abord, sur les images de dédicace dans les manuscrits, Charles comme duc n'est pas très différemment représenté que son père. Ensuite, parmi les panneaux peints, le plus célèbre est à Berlin (Staatliche Museen, Gemäldegalerie), attribué à Rogier van der Weyden vers 1460 : en buste, il est très conventionnel, ici encore comme les portraits de son père à Bruges ou à Dijon, ou de son demi-frère Antoine le Grand Bâtard ${ }^{33}$ : «le portrait se distingue par sa dignité pleine de sérieux et d'élégance [...] une conscience de soi déterminée par les idées de noblesse et de vertus aristocratiques ${ }^{34}$ ", avec bien en vue le collier de la Toison d'or. Autrement dit, l'artiste met en scène la continuité dynastique et montre au spectateur l'aptitude de Charles à hériter du duché. Sur tous ces portraits, le duc, Philippe ou Charles, tient en main un écrit ou une épée, interprété comme une allusion à son «bon gouvernement $»^{35}$. L'innovation artistique réside dans la position trois quarts, adoptée aussi par le Maître de Flémalle ou Jean van Eyck. Les copies de portraits des ducs sont multiples :

Ils avaient différentes fonctions officielles : ils servaient de portraits de suppléance, qui incarnaient le pouvoir du prince en son absence; ils jouaient un rôle souvent attesté lors des négociations accompagnant les conclusions de mariage, on les 
offrait en cadeaux à ses fidèles vassaux, à ses partisans et aux diplomates; et ils documentaient la généalogie dynastique à l'intention des sujets et des membres de la famille ${ }^{36}$. notre reliquaire. Enfin, dans des scènes bibliques, pour le flatter, le duc aurait bénéficié de la part des peintres van der Weyden et Memling de crypto-portraits. À Liège, c'est l'inverse si l'on peut dire : saint Georges recueille les traits du duc. Dès le XvIII siècle, la peinture des deux visages rend plus difficile la comparaison des traits de Charles par rapport à ceux des autres portraits conservés. Les boucles de cheveux des statuettes orfévrées tendent à la stylisation, presque en des motifs ornementaux, comme calamistrés. Les traits de Charles sont bien marqués ${ }^{37}$. Vers 1474, le médailleur italien Giovanni Candida grava le portrait du duc selon la mode antique - de profil vers la droite -, ceignant son chef de lauriers, figure plus proche encore de celle de Liège ${ }^{38}$.

\section{Charles chevalier : Alexandre, César et nouveau saint Georges}

15 Sur la figurine de Liège, Charles le Téméraire porte le collier de la Toison d'or. S'inscrivant dans la tradition des grands ordres militaires pour la reconquête de la Terre sainte, l'ordre de la Toison d'or fut créé le 10 janvier 1430 à Bruges par Philippe le Bon pour «la défense de la vraye foi $»^{39}$. L'ordre met en valeur la vertu de l'honneur, composante essentielle de l'idéal chevaleresque. Tout comme les tapisseries réalisées pour la cour de Bourgogne, les manuscrits de la bibliothèque des ducs nous informent sur l'imaginaire des princes à travers leurs lectures, comme l'histoire de Jason : héros païen, paradigme de courage et de vaillance, chef des Argonautes, il part à la conquête de la toison d'or d'un bélier merveilleux gardé par un dragon, et l'histoire de Gédéon, héros biblique et patron chrétien de l'ordre. Philippe le Bon s'était attaché les services de vingt-quatre chevaliers, selon des statuts recopiés dans de somptueux manuscrits à la décoration soignée. Par ses cérémonies d'apparat prestigieuses, l'ordre concourrait à tout l'éclat, au prestige et au faste de la cour de Bourgogne. En signe de son appartenance, chaque chevalier reçoit un collier, où est suspendue la dépouille de la toison d'un bélier. Aucun collier n'appartient au chevalier ; ils sont tous la propriété du souverain et doivent lui être restitués à la mort du bénéficiaire ${ }^{40}$. Le plus ancien collier complet conservé est au Trésor de Vienne ${ }^{41}$. Le collier miniature représenté sur notre reliquaire est une interprétation par Gérard Loyet du collier du Téméraire : c'est la plus ancienne représentation orfévrée d'un collier de la Toison d'or. Le collier représenté sur le coffret de Chimay (1472-1476) est lui aussi une copie orfévrée miniaturisée, probablement du collier porté par son commanditaire Philippe II de Croy ${ }^{42}$. Les différences entre les deux représentations de Liège et de Chimay tiennent au talent de l'orfèvre. Si les représentations picturales du collier ne manquent pas, sa représentation orfévrée au temps du Téméraire est rare. C'est dire l'intérêt de celui miniature de Liège en or, composé d'une succession de «fusils, ou briquets stylisés encadrant des cailloux ou pierres à feu, dont partent des étincelles ardentes ", la thoison d'or $y$ pendant $t^{43}$.

Devant le duc, sur le socle, est posé son heaume, empanaché de plumes d'or très finement coulées et gravées, réunies par un nœud d'émail bleu et, à ses côtés, de part et d'autre du coussin, sont posés ses gantelets. Claude Blair y voit la reproduction fidèle

Bulletin du centre d'études médiévales d'Auxerre | BUCEMA, 24.1 | 2020 
d'une " armure milanaise typique de l'époque, en partie recouverte par un gilet court à manches longues, garni peut-être à l'origine d'émaux représentant les armes de Bourgogne $»^{44}$. Ces armoiries et l'épée (aujourd'hui refaite) de Charles ont disparu, ainsi que l'attestent des marques de fixation visibles sur l'œuvre et les mentions d'archives ${ }^{45}$. Un autre élément a peut-être aussi disparu : par-dessus son armure, Charles devait sans doute porter une cotte d'armes, c'est-à-dire un vêtement de tissu, qui, ici, pourrait avoir été un gilet court à longues manches, selon la suggestion de Claude Blair. Le Goldene Rössl (vers 1405) montre ainsi le roi Charles VI avec une tunique bleue fleurdelisée et, autre exemple, dans les Heures de Simon de Varie (vers 1475), le chevalier, lui aussi en orant, est vêtu d'une cotte d'armes rouge avec motifs dorés fleurdelisés ${ }^{46}$. Ici à Liège, la repose du collier de la Toison d'or augmente notre hypothèse d'une cotte: le collier aura été détaché pour ôter la cotte (perdue), puis refixé avec des vis modernes sur l'armure ${ }^{47}$.

Derrière le duc se tient debout saint Georges ${ }^{48}$, casqué, avec ses principaux attributs (mentionnés en $1483^{49}$ ): sa lance, son étendard et, sur le dos, sa targe de joute (aujourd'hui refaite) ont disparu, ainsi qu'en témoignent une fois encore les marques de fixation subsistantes, et les archives. Son attribut iconographique traditionnel, le dragon, en émaux bleu profond et vert en ronde-bosse, s'enroule autour de ses pieds ; une flamme rouge s'échappe de sa gueule béante. La main gauche de saint Georges touche l'épaule de Charles, qu'il présente par ce geste. De la main droite, il soulève son casque en signe de salut (fig. 3).

Fig. 3 - Reliquaire de Charles le Téméraire, Trésor de Liège

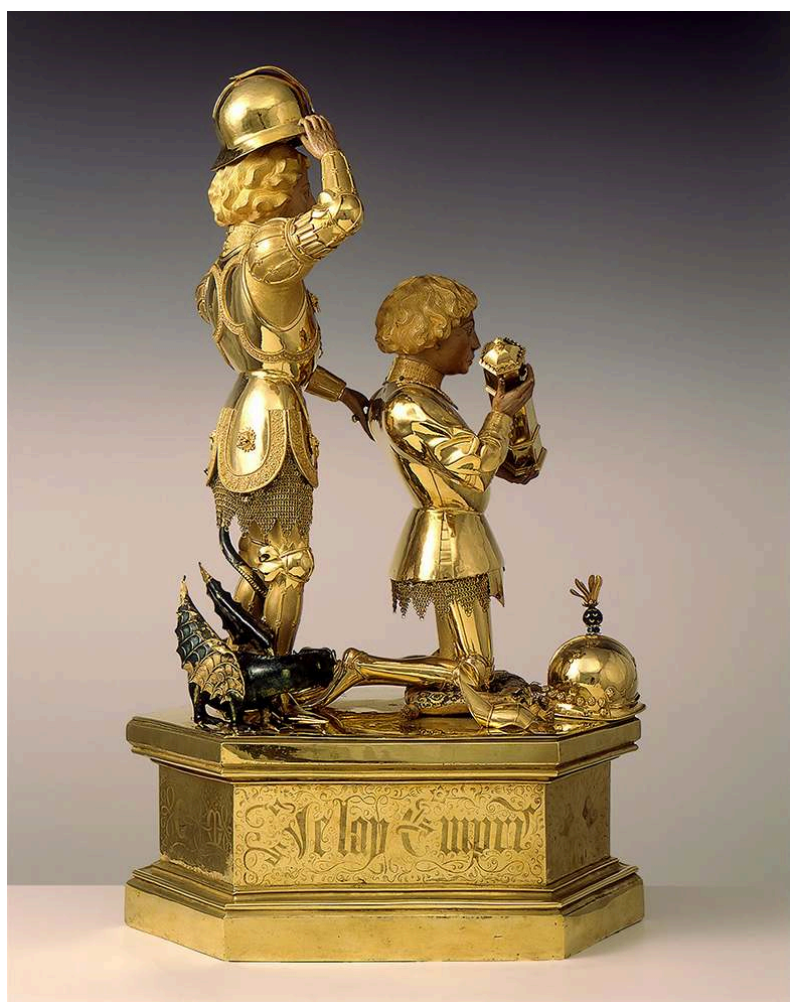

(c) Bruxelles, IRPA

Saint Georges, le saint patron des chevaliers, est omniprésent dans l'iconographie bourguignonne. Par mimétisme des visages, Charles est présenté comme un nouveau 
saint Georges ${ }^{50}$. Il a fait le vœu de la croisade avec son père Philippe le Bon, qui, lors du fameux banquet du faisan en 1454, avait invité ses convives à prendre avec lui la croix contre les Turcs ${ }^{51}$. La chute de Constantinople en 1453 avait bien sûr impressionné les esprits. Jean Richard rappelle l'intérêt constant que les ducs de Bourgogne ont manifesté pour la croisade, qui demeure, même si ce n'est plus qu'un rêve, «la plus haute (entreprise) qu'un prince puisse se proposer et proposer à ses chevaliers ». Le point final de ces velléités ducales fut-il, en 1464, «l'expédition du bâtard de Bourgogne qui, après un fait d'armes devant Ceuta, s'acheva à Marseille lorsque la mort du pape Pie II, promoteur de la croisade, fit avorter le projet $»^{52}$ ? En 1473, le légat du pape rappelle aux chevaliers du chapitre de la Toison d'or leur engagement ${ }^{53}$.

L'armure de Charles est réaliste comme d'époque, celle de saint Georges est " antiquisante », selon la représentation fantaisiste de l'Antiquité romaine que l'on se faisait encore au $\mathrm{xV}^{\mathrm{e}}$ siècle, afin de créer une distanciation par rapport au monde contemporain ${ }^{54}$. Le contraste entre les deux armures, avec le souci du détail apporté à l'armure de saint Georges en opposition à la simplicité de celle de Charles, accrédite l'hypothèse pour Charles d'une cotte d'armes perdue ${ }^{55}$.

\section{Ex-voto et appropriation : inspiration et technique de l'artiste}

L'artiste est Gérard Loyet, orfèvre travaillant au service des ducs de Bourgogne, mentionné dès 1449, dont Hugo van der Velden retrace avec soin toute la carrière. Originaire de Dijon, Gérard Loyet devient orfêvre et varlet de chambre, confident de Charles le Téméraire qui le nomme, en 1467, général maitre de la Monnaie de Bourgogne ${ }^{56}$.

Les sources d'inspiration de Loyet sont depuis longtemps bien connues. La célèbre peinture de la Madone au chanoine Joris (Georges en flamand) van der Paele de Jean van Eyck - Bruges, musée Groningue, 1434-1436, jadis dans l'église Saint-Donatien - montre un saint Georges semblable ${ }^{57}$. Protégé et présenté par son saint patron, le chanoine à genoux prie devant la Vierge, assise au centre, et saint Donatien à gauche. Dans sa composition, l'orfèvre Loyet remplace le chanoine par le duc Charles : dans son esprit et sans les représenter, la Vierge et saint Donatien deviennent sainte Marie et saint Lambert, les deux patrons de la cathédrale de Liège, dont le Téméraire est devenu le vassal et le protecteur de leurs biens terrestres. L'armure de saint Georges, plus élaborée que celle de Charles, fait aussi penser à une autre peinture de Jean van Eyck, le volet du triptyque de Dresde montrant saint Michel, que l'on retrouve aussi, en détail grisaille, sur la jouée basse de la stalle des anges chanteurs de l'Agneau mystique à Gand. Sur ce dernier chef-d'œuvre, le groupe des chevaliers du Christ incorpore saint Georges. Les portraits d'orants présentés par leurs saints patrons ne manquent pas. Au saint patron des chevaliers le duc témoigne une profonde dévotion, alors que saint André est, quant à lui, le patron de la Bourgogne ${ }^{58}$.

D'autre part, l'orfèvrerie d'époque fournit quelques beaux exemples d'œuvres apparentées par la technique, le sujet ou l'intention exprimée ${ }^{59}$. Seuls une quarantaine d'objets ont survécu, alors qu'archives et représentations anciennes prouvent le grand succès de cet $\operatorname{art}^{60}$. La cour de Bourgogne est friande de joyaux d'or émaillés, cadeaux princiers par excellence. Philippe le Hardi aurait « inauguré la mode des statuettes d'or 
figurant des saints ${ }^{61}$. Jean sans Peur faisait répandre ses devises sur les orfèvreries qu'il commandait. Parmi les œuvres disparues, Philippe le Hardi offrit en 1397 à Charles VI un saint Michel en or émaillé terrassant... un dragon. Comment négliger le souvenir de ces objets précieux dans la création du reliquaire de Liège ? On les connaît, on en hérite, on les admire ${ }^{62}$. Même antérieur d'une cinquantaine d'années, et outre la technique d'orfèvrerie, le Goldenes Rössl offre avec Liège quelques comparaisons ${ }^{63}:$ la position des personnages en orants, Charles VI et son écuyer tenant en mains le heaume royal, tous deux en armures sous leurs habits, le traitement des cheveux calamistrés en or ciselé, le magnifique bleu des vêtements.

Le casque du saint Georges de Liège porte une agrafe en forme de plume, fixée par une rose émaillée blanche à perle. Ce motif est à la mode ${ }^{64}$. Il pouvait, comme bijou, servir aussi de fermail ou de pendentif. La rose bourguignonne la plus célèbre est le joyau de Charles le Téméraire tombé aux mains des Suisses à Grandson et qui n'est connu que par une aquarelle ; il était fait d'une grosse pierre précieuse rouge de forme irrégulière avec ses douze pétales blancs hérissés d'épines d'or. La couronne de Marguerite d'York - Aix-la-Chapelle, Domschatzkammer - comporte des roses blanches émaillées, les armes et les initiales « $C$ » et « $M$ »; elle fut offerte par la duchesse à Notre-Dame d'Aix en $1475^{65}$. Alors que Charles offre un ex-voto à saint Lambert, Marguerite offre une couronne à la Vierge, deux saints ainsi honorés qui sont les deux patrons de la cathédrale de Liège, dont le diocèse comprenait Aix-la-Chapelle. Aix est la ville du couronnement du roi des Romains et l'évêque de Liège y assiste généralement.

\section{Bâtardise, fidélité et troisième mariage}

Le mystère du groupe orfévré et son attrait résident dans les différentes lectures qui en ont été proposées, outre bien entendu l'art de l'orfèvre. Plusieurs sens de lecture se superposent en ces cinq ans (1467-1471) pendant lesquels les événements s'accumulent. Le mariage de Charles et de Marguerite (1468) y est commémoré par l'inscription des initiales des nouveaux époux sur le socle ${ }^{66}$. Or, on oublie que saint Lambert est très tôt perçu, cent cinquante ans après sa mort vers 696-705, comme le défenseur de la fidélité conjugale, une invocation qui, en fonction des circonstances, connaîtra ses heures de gloire au Grand Siècle ${ }^{67}$. D'abord, déjà dès 1455 selon des rumeurs, puis en 1466, les Dinantais avaient insulté le duc en le traitant de villain bastard, né d'une relation entre sa mère la duchesse Isabelle de Portugal et le prince-évêque de Liège Jean de Heinsberg $(1419-1455)^{68}$. Le Téméraire, très lié à sa mère, a une haute idée de l'honneur personnel et ne pouvait tolérer que sa légitimité fût mise en doute ${ }^{69}$. Charles place-t-il aussi son récent mariage sous la protection du saint? La piété du Téméraire est connue et multiforme ${ }^{70}$. Dans une cour aussi cultivée et raffinée que celle des ducs de Bourgogne, nul doute que ces « hystoires» de saints soient connues ${ }^{71}$. Les martyrs, premiers parmi les saints, continuent à exercer une fascination sur les mentalités médiévales dans leurs fonctions d'intercesseurs et de protecteurs ${ }^{72}$ : Lambert comme Georges sont des martyrs. D'autre part, l'imaginaire de Charles le Téméraire est tout peuplé de héros antiques et de mythologie chevaleresque. Par les victoires de Jules César ou de Trajan, la guerre se déroule en panneaux sur les superbes tapisseries du musée Historique de Berne, qui conserve aussi les «petits patrons " pour une tapisserie sur « Alexandre en Orient $»^{73}$. Parallèlement au mimétisme entre Charles et saint Georges observé sur le reliquaire de Liège, le duc s'assimile ici aux grands capitaines de l'Antiquité, dont il se 
considère le descendant ${ }^{74}$ : "Le duc se mettait ainsi en scène comme un monarque glorieux, mais aussi comme un "autre Hercule", un "second Alexandre" ou un "nouveau César"75.» Ces documents textiles exceptionnels nous plongent, à des fins de propagande, au cœur des victoires bourguignonnes ${ }^{76}$.

Tout ceci correspond parfaitement au portrait psychologique du Téméraire. Le portrait est nuancé chez Werner Paravicini, qui insiste sur son « sens exacerbé de l'honneur $»^{77}$. Pour Hugo van der Velden, les effigies en or et en cire étaient «le résultat d'une combinaison de dévotion et d'assurance personnelle, de superstition et de vanité : Charles était égocentrique, ambitieux, pieux et plein d'ostentation ${ }^{78} »$. L'appropriation artistique qu'opère Gérard Loyet par son reliquaire et la mise en valeur de la figure du duc ne cachent-elles pas d'autres motivations? Charles le Téméraire aimait offrir comme œuvres votives des sculptures orfévrées en argent ou en or qu'il faisait accompagner de sa propre effigie, en armure ou à cheval. Le remerciement pour la protection accordée par le saint ex-voto se doublait ainsi d'une intention politique, fortement affichée ${ }^{79}$. Le Téméraire offrit ainsi d'autres effigies en or à Notre-Dame de Boulogne, Notre-Dame de Hal, Notre-Dame de Scheut, Notre-Dame d'Aardenburg, Saint-Claude en Jura, Saint-Adrien de Grammont, Saint-Sébastien de Linkebeek, ou en cire à Grammont, Paray-le-Monial et Florence ${ }^{80}$, preuves de son pouvoir, de son prestige. Seule son " ymage d'or » offerte à Liège a survécu ${ }^{81}$.

Le splendide et raffiné Livre de prières de Charles le Téméraire - Los Angeles, The J. Paul Getty Museum, Ms. 37 - engage le spectateur dans l'intimité pieuse du duc par son texte et par ses images ${ }^{82}$. Trois miniatures montrent le duc en prières: sur deux, il est présenté par saint Georges (fol. $1^{\mathrm{v}}$ et $6^{\mathrm{r}}$ ) et, sur l'autre, par un ange $\left(68^{\mathrm{r}}\right)$. Sur la première, Charles porte un long vêtement de brocart, sur la seconde il est en armure, mais il ne porte pas la Toison d'or ${ }^{83}$. On pourrait presque écrire que c'est la plus ancienne représentation connue de notre reliquaire.

\section{Charles le féal et politique vassal de saint Lambert de Liège}

27 Aux termes du traité imposé aux Liégeois dans les mois qui suivent leur défaite à Montenaken (20 octobre 1465), Liège doit recevoir Charles, lieutenant des armées de son père, comme son "gardien et avoué souverain héréditaire ». Cette expression ne peut manquer de nous faire penser à l'Avoué de Hesbaye ${ }^{84}$, qui, en temps de guerre, allait chercher sur l'autel de la Sainte-Trinité, dans la cathédrale de Liège, le gonfanon de saint Lambert, fédérateur des troupes liégeoises ${ }^{85}$. Charles entre à Liège mais la lutte reprend. En septembre 1467, les milices liégeoises prennent Huy, où s'était réfugié le prince-évêque. D'après Adrien Oudenbosch, ils célèbrent leur victoire autour d'une statue de saint Lambert installée sur la grand-place et crient « Notre-Dame et Saint Lambert » en appelant aux armes ${ }^{86}$. Les Liégeois sont d'ailleurs dans le même souvenir lorsque le 13 octobre 1467 ils célèbrent le «triomphe » de Steppes, à la veille de leur nouveau combat avec les troupes bourguignonnes : à Steppes, en 1213, ils avaient défait l'armée brabançonne, or Charles est aussi duc de Brabant. Cette victoire liégeoise de 1213 est l'un des grands faits d'armes d'Ancien Régime, commémoré à travers toute la liturgie. En 1467, ils amènent en procession la statue de « Notre-Dame de Steppes » de Montenaken à la cathédrale. Pourtant leur défaite sera totale à Brustem. 
Nous pousserions l'analyse plus loin encore. La visite du Téméraire en novembre 1467 à Liège pour vénérer les reliques de saint Lambert lui permet peut-être d'acquérir un doigt de la main droite du saint, relique corporelle hautement symbolique ${ }^{87}$. L'étendard du duc, à l'image de saint Georges et à la devise du Téméraire, est suspendu dans la cathédrale comme signe de sa protection. L'année de son avènement comme duc de Bourgogne (1467), il veut offrir un ex-voto à la cathédrale «à Monseigneur saint Lambert ». L'ex-voto va peu à peu se muter en reliquaire. Il faut ajouter que la présence d'une telle relique dans les mains du duc est significative à plus d'un titre. Au Moyen Âge, saint Lambert est considéré comme le véritable propriétaire de la terre de l'Église de Liège, la «terre de saint Lambert $"^{88}$. Dans une société où le symbolique imprègne toutes les mentalités, le Téméraire veut signifier aux Liégeois qu'il est devenu le maître du pays et c'est l'image qu'il veut donner de lui. Charles vient de tailler en pièces les milices liégeoises et il veut clamer haut et fort sa victoire et sa mainmise sur la principauté de Liège ${ }^{89}$. Imposer son image à la face des Liégeois, et, en outre, tenant en mains une relique de leur saint patron, n'est-ce pas une double provocation " pieuse »? Avec bien sûr tout le respect dû à saint Lambert: le duc est à genoux, il a ôté ses gantelets, et saint Georges le salue. Devenu le haut protecteur de l'Église et du pays de Liège, le duc Charles entendait marquer l'événement, de manière ostentatoire, par l'offrande de cet objet magnifique, chargé de fortes valeurs symboliques : protégé d'une main tutélaire par saint Georges, patron des hommes d'armes et de la guerre, Charles le Téméraire, en tenue militaire, s'identifiait à lui par la similitude des traits et venait s'agenouiller devant sainte Marie et saint Lambert, protecteurs célestes de la cathédrale et du pays de Liège. Le duc, « gardien et avoué » de l'Église de Liège et de sa terre, c'est-à-dire son défenseur laïc, avait été investi de sa charge par un objet exceptionnel : un fragment de la main droite de saint Lambert dont Charles, désormais, était le vassal. Le duc de Bourgogne, en effet, qui a déposé devant lui son casque et ses gantelets, reçoit de saint Lambert lui-même la précieuse relique utilisée comme objet d'investiture vassalique. En d'autres termes, le reliquaire de Charles le Téméraire n'est pas un don expiatoire. Il est, bien au contraire, l'expression de la toute-puissance du duc-avoué, protégé par saint Georges ${ }^{90}$ et choisi par saint Lambert lui-même pour défendre, par la force des armes, son église, ses biens d'ici-bas et ses sujets... Il est certain que le reliquaire, commandé en 1467 et offert à la cathédrale de Liège en 1471, a subi, entre-temps et en raison des circonstances, l'une ou l'autre modification par rapport au projet initial. Mais l'essentiel du message fut vraisemblablement préservé. Les chroniqueurs liégeois s'évertuent à le masquer par un prétendu désir d'expiation du sac de Liège de $1468^{91}$.

29 C'est une véritable démonstration de force de la part d'un duc de Bourgogne qui s'approprie les codes politiques et symboliques propres à l'État liégeois ${ }^{92}$. L'interprétation politique pourrait peut-être encore être développée avec l'idée du prince protecteur du bien public, la chose publicque, dont il est le gardien ${ }^{93}:$ «Il serait le défenseur de l'intérêt général face aux particularismes égoïstes, façon tout à fait efficace de présenter les bienfaits de son gouvernement, a fortiori sur des terres nouvellement conquises ${ }^{94}$. "

30 D'un point de vue militaire, en général, la démonstration de force bourguignonne s'inscrit dans une stratégie parfaitement rodée et une " propagande musclée » destinée à déstabiliser l'ennemi ${ }^{95}$. «Dinant et Liège sont victimes d'un acte politique, visant à assujettir, une fois pour toutes, la principauté épiscopale à la domination 
bourguignonne autant qu'à avertir les grandes villes flamandes des dangers d'une révolte, véritable crime de lèse-majesté, contre leur prince nature ${ }^{96}$. " Les sacs de Dinant (1466) et de Liège (1468) sont aussi des «actes de justice et de propagande, destinés à souligner la majesté du duc, la puissance militaire bourguignonne comme la faiblesse de l'adversaire. Appliqué à la lettre par un prince soucieux de sa réputation de juge rigoureux, le droit de la guerre joue un rôle crucial dans cette propagande ${ }^{97}$. »

\section{En guise de conclusion, l'œuvre et son public : le pouvoir par l'art et par les idées}

31 Devant l'orfèvrerie, et toute la fascination qu'elle exerce, les questions fusent, l'observation progresse, les sources sont (re)sollicitées pour cerner les intentions du duc et comprendre le travail de l'artiste. Le reliquaire est-il un témoin de mauvaise conscience ou un "don de joyeux avènement ${ }^{98}$ ? Saint Lambert s'est-il vengé à Nancy, en 1477, par la mort horrible du grand-duc d'Occident en pleine bataille9 ${ }^{99}$ Ou, bien au contraire, Charles le Téméraire a-t-il fait un cadeau à saint Lambert pour le remercier des victoires remportées sur les Liégeois? Seul rescapé de ces magnifiques ex-voto offerts, celui de Liège n'est pas, comme certains chroniqueurs l'écriront, une œuvre expiatoire par une quelconque résipiscence pour le sac de la ville mais un ex-voto comme les aimait le duc. Serait-ce l'affichage de son emprise sur la principauté dans une sorte de mise en scène de la puissance de ses armées aux yeux des Liégeois? Ferveur religieuse ou machiavélisme politique avant la lettre? Charles était-il convaincu de l'intervention du saint en sa faveur, comme du soutien de saint Georges $^{100}$ ? Enfin, celui qui "aimoit honneur et craignoit Dieu " plaça-t-il aussi son récent mariage sous la protection de saint Lambert ${ }^{101}$ ?

En réalité, la confection du reliquaire, entamée dès 1467, doit être mise en rapport avec la nouvelle position politique de Charles le Téméraire au sein de la principauté de Liège et de son évolution dans ces années charnières. En 1466, le duc de Bourgogne était devenu le "gardien et avoué souverain héréditaire » des églises et du pays de Liège. Il le démontra, du reste, de manière symbolique et spectaculaire, le 30 octobre 1468, dans l'indescriptible désordre $\mathrm{du}$ sac de Liège: Philippe de Commynes, le célèbre mémorialiste au service du duc de 1440 à 1470, vit alors, de ses yeux, le duc Charles défendre personnellement « la grant eglise de Sainct-Lambert, ou ses gens vouloient entrer par force, pour prendre des prisonniers et des biens ", et qu'il « tua ung homme de sa main $»^{102}$ ! De ce fait, Charles s'était imposé comme le protecteur et le maître du pays. Son mariage s'adjoignit en 1468 au message, sorte de parachèvement : de surcroît, le saint patron du diocèse de Liège est aussi le défenseur de la fidélité conjugale et saint Georges, patron de l'ordre de la Jarretière, un saint bien à l'honneur outre-Manche, patrie de sa nouvelle épouse.

Soixante ans plus tôt, pour commémorer sa victoire sur les Liégeois et leur " desconfiture », Jean sans Peur avait fait réaliser six tapisseries de haute-lisse, dont une sur la bataille d'Othée et une autre sur la reddition de Liège et des bonnes villes. Jean de Bavière en avait aussi commandé deux sur le même thème ${ }^{103}$. C'est l'aspect de la communication politique et de la propagande bourguignonne que l'on touche ici: l'usage des objets dans la construction symbolique des pouvoirs. Faute d'encore posséder aujourd'hui ces tapisseries, on en possède des descriptions et surtout l'utilisation qui en est faite lors de cérémonies fastueuses où elles sont tendues. Cette 
communication politique s'exerce aussi à travers l'enluminure et la peinture ${ }^{104}$. Alors, pourquoi ne pourrait-elle le faire à travers l'orfèvrerie ? La communication incorpore «le spectacle de la justice, la droiture et la loyautétes »: l'honneur et la fierté du Téméraire sont parmi les messages forts à déchiffrer du reliquaire de Liège.

Reçu : 26 février 2020 - Accepté : 26 juin 2020

\section{NOTES}

*. Que Jean-Pierre Roland, inspecteur général honoraire des Ponts et Chaussées (Belgique), reçoive la dédicace de cet article en amicale reconnaissance de son soutien au Trésor de la cathédrale de Liège pendant les derniers travaux de rénovation. Nous exprimons notre vive gratitude à Werner Paravicini (université de Kiel), qui a bien voulu relire notre texte et nous faire part de ses remarques, sans que nous engagions sa responsabilité scientifique. Cet article a pris place dans le Bucema, à la suggestion de Christian Sapin, et au soin de toute l'équipe du Centre d'études médiévales d'Auxerre, que nous remercions très vivement. Adresse de l'auteur: philippe.george@uliege.be.

1. Entre 1849 et 1852, Léon de Laborde publie ses trois volumes sur Les ducs de Bourgogne en exploitant pour la première fois le matériel archivistique de l'administration ducale, où se trouve la mention du versement à l'orfèvre Gérard Loyet, voir H. VAN DER VELDEN, The Donor'Image. Gerard Loyet and the votive portraits of Charles the Bold, Turnhout, 2000. La bibliographie est vaste. Ici nous nous sommes concentrés sur le neuf et l'inédit du sujet et nous n'avons retenu que les références bibliographiques indispensables. Nous renvoyons à notre ouvrage pour toute précision utile : "L'ymage d'or » du duc de Bourgogne (1467-1471). Art et histoire au temps du Téméraire, éd. J. TOUSSAINT, Namur, 2020, ainsi que pour tous nos remerciements.

2. J. HELBIG, «Une œuvre de Gérard Loyet, graveur de sceaux, orfèvre et valet de chambre du duc de Bourgogne ", Revue de l'art chrétien, $3^{\mathrm{e}}$ série, 26 (1883), p. 271-278.

3. B. SCHNERB, L'État bourguignon, 1363-1477, Paris, 1999 et ID., «Les ducs de Bourgogne et leurs «pays de par-deçà » au Xve siècle », in B. BousMANNE et T. DELCourt (éd.), Miniatures flamandes, 1404-1482, Paris/Bruxelles, 2011, p. 38-46; M. BooNE, "Les Pays-Bas bourguignons. Prospérité promise ou conquise ? », in EID. (éd.), Miniatures flamandes..., ibid., p 47-54.

4. L'œuvre a subi un examen à l'Institut royal du patrimoine artistique à Bruxelles en 1980 et 1992, et son entretien régulier est depuis lors assuré au Trésor par le restaurateur Louis-Pierre Baert, que nous voulons encore remercier très vivement pour toute son activité gracieuse et efficace pendant de nombreuses années au Trésor de Liège. Hauteur avec base $53 \mathrm{~cm}$, largeur $32 \mathrm{~cm}$ et profondeur $17,5 \mathrm{~cm}$; poids total $5,060 \mathrm{~kg}$, dont 2,113 $\mathrm{kg}$ d'argent doré du socle et 2, $947 \mathrm{~kg}$ d'or.

5. Il s'agit d'une expression issue du langage du tournoi. La devise du Téméraire résonne en une polysémie voulue, chevaleresque, amoureuse et politique. Le plus spectaculaire est l'inscription de la devise sur les bannières, accompagnée ou non de la figure de saint Georges, dont la grande aujourd'hui conservée à Soleure.

6. Sur les armoiries du Téméraire: W. PARAVICINI, «Le parchemin de Montpellier, une image troublante du règne de Charles le Téméraire ", Journal des savants, 2010, p. 314-316.

7. Les initiales se retrouvent sur le collier porté par Marguerite d'York sur le petit portrait conservé au Louvre. Elles sont fréquentes dans les manuscrits et sur les tapisseries. 
8. N. STRATFORD, « "De opere punctili”. Beobachtungen zur Technik der Punktpunzirung um 1400 », in R. BAUMSTARK (éd.), Das Goldene Rössl, Munich, 1995, p. 131-145. La coupe de Jean sans Peur (Karlsruhe, Landesmuseum), qui aboutira dans le trésor du Téméraire, est décorée de gravures au pointillé.

9. E. TABURET-DELAHAYE, « L'orfèvrerie », in C. PRIGENT (éd.), Art et société en France au XVe siècle, Paris, 1999, p. 273.

10. La relique, identifiée par le $\mathrm{D}^{\mathrm{r}}$ Jean-Pierre Pirenne, a été replacée le 9 avril 2001 dans le réceptacle nettoyé et munie d'une attestation scellée par $\mathrm{M}^{\mathrm{gr}}$ Albert Houssiau, évêque de Liège.

11. W. PARAVICINI, Guy de Brimeu. Der burgundische Staat und seine adlige Führungsgeschichte unter Karl dem Kühnen, Bonn, 1975, p. 228 sq. et P. GEORGE, «Le trésor des reliques de la cathédrale SaintLambert de Liège ", Bulletin de l'Institut archéologique liégeois, 117 (2013), p. 82-83 : un document mentionnant Humbercourt (en 1469) retrouvé dans la châsse de saint Lambert lors de son ouverture en 1489.

12. Humbercourt vit la première fois les reliques de saint Lambert le 12 septembre 1466 et, le 27 janvier 1469, il obtint une relique détachée des pieds (cf. w. PARAVICINI, Guy de Brimeu..., ibid., p. 122). Hugo Van der Velden (p. 117) fait remarquer qu'il s'agit d'une relique des pieds de saint Lambert alors que précisément le lieutenant souffrait d'une blessure au pied (cf. W. PARAVICINI, Guy de Brimeu..., ibid., p. 196).

13. Selon Adrien d'Oudenbosch et Jean de Looz, commentés par W. Paravicini (cf. Guy de Brimeu..., ibid., p. 233). Humbercourt donne 30 marcs, soit $7 \mathrm{~kg} 380$ gr. d'argent, selon É. PONCELET, «Les auteurs du buste-reliquaire de saint Lambert», Leodium, 1935, p. 4. Développements dans P. COLMAN, « Le buste-reliquaire de la cathédrale Liège et sa restauration », Bulletin de l'Institut royal du patrimoine artistique, 14 (1973-1974), p. 416 et https://orbi.uliege.be/handle/2268/245902.

14. H. VAN DER VELDEN, The Donor'Image..., op. cit., p. 99-100, et p. 338-339 : documents des dépenses (1468-1469) faites pour « les quatre orfrois a metttre sur quatre capes [...] une casuble avec les habitz des dyacre et soubzdiacre, et sur iceulx orfrois faire tout au long la vie saint Lambert » (et) les «parament d'autel, chappes, chasubles et autres parties [...] a donnez a l'eglise saint Lambert de Liege » en 1468. Le brodeur bruxellois Jehan Marchant les « a faictes, et en icelles mis et figuré la vie de monseigneur saint Lambert », avec Jehan Franciere, cousturier demourant a Lille. 15. Sur le contexte général, voir: A. MARCHANDISSE, I. VRANCKEN-PIRSON et J.-L. KUPPER, «La destruction de la ville de Liège (1468) et sa reconstruction ", in Destruction et reconstruction des villes du Moyen Âge à nos jours, Bruxelles, 1999, p. 69-96 ; M. BOONE, "Charles le Téméraire face au monde urbain : ennemis jurés et fatals? », in K. OsCHEMA et R. C. schwingEs (éd.), Karl der Kühne von Burgund. Fürst zwischen Europäischem Adel und der Eidgenossenschaft, Zurich, 2010 p. 185-201; W. PARAVICINI, «Lüttich, 26. November 1467. Ein Brief Karls des Kühnen an Guy de Brimeu », in G. ANNAS et J. NOWAK (éd.), Et l'homme dans tout cela? Von Menschen, Mächten und Motiven. Festschrift für Heribert Müller, 2017, p. 687-789. Sans oublier l'introduction historique, sous la plume alerte et intelligente de Jean Lejeune, du catalogue de l'exposition Liège et Bourgogne, Liège, 1968, p. 85.

16. C'est Hugo Van der Velden, le premier, qui le relève. J. stiennon, dans Jean Chapeauville (1551-1617) et ses amis. Contribution à l'historiographie liégeoise, éd. critique du texte latin, trad. française et notes philologiques de R. HOven, Bruxelles, 2004. Jean Chapeauville retranscrit la chronique d'Adrien d'Oudenbosch et ajoute «tenentis de reliquiis S. Lamberti in manibus » (J. CHAPEAUVILLE, Qui gesta pontificum Tungrensium [...], Liège, t. 3, 1616, p. 188).

17. REMACLE DE MOHY, Le cabinet historial [...], Liège, 1610, p. 191. Ce n'est pas le cas, par exemple, dans l'Instrumentum de 1483 (P. GEORGE, Le Trésor des reliques..., op. cit., p. 115), ni dans l'armorial de la Toison d'or de la bibliothèque de Dijon (1583-1584) exposé à Beaune (J. RICHARD, « Les fidèles de la duchesse Marie et les soulèvements de 1477-1479 dans le duché ", in Bruges à Beaune. Marie, l'héritage de Bourgogne, Paris/Beaune, 2000, p. 66 et P. BRUYÈRE, «La plus ancienne représentation connue de l'ex-voto offert par Charles le Hardi à la cathédrale de Liège (circa 1584) », Bulletin de la 
Société royale le Vieux-Liège, 284 (1999), p. 833-856). La chronique qui accompagne cette représentation rapporte : « [...] et quil se feroit faire dor fin au naturel, com(m)il se void, encoires aujourdhuy en grande solemnité, et de grand pris et valeur, avec st. George son patron, quy ladresse vers st. Lambert en genoulx, com $(m)$ le celluy quy prie poyr grace, et misericorde » (ID., p. 853 : Hugo Van der Velden est très critique sur cet article, qui utilise fortement et à géométrie variable sa thèse inédite, p. 102).

18. Les mentions s'enchaînent ensuite : Pierre Bergeron (1619), Barthélemy Fisen (1642), jusqu'à l'inventaire de 1803 (H. VAN DER VELDEN, The Donor'Image..., op. cit., p. 337-345).

19. O.-J. THIMISTER, Essai historique de l'église de S. Paul ci-devant collégiale aujourd'hui cathédrale de Liège, Liège, 1867, p. 235 et 366 (appendice), et ID., Histoire de l'église collégiale de Saint-Paul actuellement cathédrale de Liège, Liège, 1890 ( $2^{\mathrm{e}}$ éd.), p. 548. Comme chanoine de la cathédrale, Thimister a pu faire procéder à l'ouverture du reliquaire, ce qui lui a donné accès à l'authentique. Il l'aura retranscrite sur le papier qui aujourd'hui l'accompagne.

20. Bruges à Beaune..., op. cit., p. 102-103 (avec les belles synthèses de J.-P. Soisson, B. Schnerb, W. Blockmans, J. Richard et M. Madou) et Trésors de cathédrales d'Europe. Liège à Beaune, Paris/ Beaune, 2005, p.112-115, et notre article ici, dans le Bucema, éd. en ligne [https:// journals.openedition.org/cem/719].

21. S. MARTI, T.-H. BORCHERT et G. KECK (éd.), Charles le Téméraire (1433-1477). Faste et déclin de la cour de Bourgogne, catalogue de l'exposition au musée Historique de Berne en 2008, au Kunsthistorisches Museum de Vienne en 2009 (Bruxelles, 2008, en néerlandais, anglais et allemand), et en 2010 à Bruges au Groeningemuseum ( $2^{e}$ éd., avec une autre couverture), $n^{\circ} 66$ p. 252-253. Nous voudrions à nouveau remercier très vivement notre collègue Susan Marti du musée de Berne, qui n'a pas ménagé ses efforts, non seulement pour donner au reliquaire une place de choix dans les trois expositions, mais aussi pour satisfaire nos desiderata dans le cadre de la conservationrestitution-restauration de la pièce, sans oublier notre association aux remarquables publications qu'elle dirigea magistralement.

22. P. GEORGE, «Le reliquaire de Charles le Téméraire du Trésor de la cathédrale de Liège. Un message à déchiffrer ", Annales de Bourgogne, t. 74 (2002), p. 3-23 ; ID., « Le reliquaire du Trésor de la cathédrale de Liège, conservation, restauration et imagination ", in N. GRAMACCINI et M. C. SCHURR (éd.), Kunst und Kulturtransfer zur Zeit Karls des Küknen, Berne, 2012, p. 49-57.

23. En 1998, À la cour de Bourgogne. Le duc, son entourage, son train, éd. J.-M. CAUCHIES, inaugurait la collection Burgundica. L'atelier du 30 novembre 2018, organisé par Éric Bousmar à Bruxelles, La médiation du passé bourguignon dans la Belgique fédérale et ses entités était significatif du succès croissant de la période. Cf. Centre européen d'études bourguignonnes: https:// ceeb.hypotheses.org/ et http://www.prosopographia-burgundica.org/.

24. Flanders in the XVth Century. Art et civilisation, Bruxelles/Détroit, 1960, n 133, p. 298-300.

25. Le perron liégeois est le monument-fontaine de la place du marché à Liège : la colonne de justice, emblème primitif du pouvoir princier, s'est muée progressivement en symbole des libertés de la «patrie liégeoise » : J.-.L. KUPPER et P. GEORGE, Charles le Téméraire. De la violence et du sacré, Liège, 2007, p. 23-25.

26. Hugo Van der Velden fait une très longue analyse historique de l'ex-voto (cf. The Donor'Image..., op. cit., p. 191 sq.). A.-J. BIJSTERVELD, Do ut des, Hilversum, 2007.

27. J.-M. CAUCHIES, Louis XI et Charles le Hardi. De Péronne à Nancy (1468-1477) : le conflit, Bruxelles, 1996. Nous partageons entièrement l'opinion de Jean-Marie Cauchies, très étayée dans les sources et les travaux, sur le surnom de Charles, qu'il préfère appeler « le Hardi », mais il est fort difficile de le lui changer en français après autant de siècles d'utilisation, plus encore ici en histoire de l'art et pour le grand public. L'épithète de "téméraire " appliquée à Charles de Bourgogne apparaît tôt, mais est tardivement adoptée par une historiographie essentiellement française qui condamne a priori l'action du duc en jetant sur lui un discrédit fâcheux et anhistorique. Grâce à 
l'ouvrage de Jean-Marie Cauchies, on évite la vision réductrice gallocentrique d'un affrontement Charles/Louis XI, en affirmant les ambitions impériales du duc. «Les qualificatifs des diverses langues révèlent plusieurs appréciations du personnage : les Allemands parlent de Karl der Kühne (le hardi), les Néerlandais de Karel de Stoute (le fier), les Anglais de Charles the Bold (le hardi) mais également de Charles the Rash (le précipité ou irréfléchi) alors que les francophones le qualifient unanimement, sauf certains Belges, de Téméraire (risque-tout, casse-cou), ce qui est plutôt péjoratif» (w. PARAVICINI, " "Folie raisonnante". Charles le Téméraire, duc de Bourgogne (1433-1477) », in S. MARTI et alii, Charles le Téméraire..., op. cit., p. 39).

28. [...] dux Carolus [...] misit ecclesiae Sancti Lamberti [...] duas argenteas imagines nobilier deauratas (Jean de Looz) / [...] In die Valentini misit dux ecclesia Leodiensi pulchra jocalia, scilicet S. Georgium (Adrien d'Oudenbosch) : P. GEORGE, «Le trésor des reliques... », op. cit., p. 63-141.

29. Histoire générale des événements dans W. PARAVICINI, Karl der Kühne. Das Ende des Hauses Burgund, Göttingen/Zürich/Frankfurt a.M., 1976 et R. VAUGHAN, Charles the Bold, Londres, 2002 ( $1^{\text {re }}$ éd. 1973).

30. «Les dix escuz d'or aux reliques de saint Lambert de Liege, que mondit seigneur y fist offrir quant il visita lesdites relicques, et les six escuz aux coustres de l'eglise dudict saint Lambert pour leur vin, d'avoir tiré icelles relicques hors du tresor ", éd. H. VAN DER VELDEN, The Donor'Image..., op. cit., p. 337 et w. PARAVICINI, Guy de Brimeu..., op. cit., p. 236, n. 571.

31. Joseph Braun parle d'un "reliquaire votif étrange». Un laïc qui tient à mains nues des reliques, n'est-ce pas aussi un pas de plus dans la direction de la spiritualité laïque ? À mettre en parallèle, par exemple, à l'époque avec la multiplication des livres de piété personnels, ces livres d'heures de dévotion privée, ou, en peinture, avec l'abandon de l'antique perspective morale et le début des portraits individuels de laïcs.

32. Un exemple antérieur, tout aussi farci d'algorithmes de Liège, de Bourgogne et de croisade, est relevé par Alain Marchandisse, cf. «Le prince-évêque de Liège Jean de Heinsberg (1419-1455) : un modèle pour le Saint Georges de Pisanello?», en ligne [https://orbi.uliege.be/bitstream/ 2268/184496/1/Heinsberg-Pisanello.pdf].

33. Dit «L'homme à la flèche », Bruxelles, vers 1460, voir D. BARBASON, Bulletin du Trésor de Liège, p. 6-8, en ligne [http://www.tresordeliege.be/publication/pdf/020.pdf]. Comme portraits en pied, on pense à celui de Nicolas Rolin sur le polyptyque des Hospices de Beaune ou à ceux d'autres membres de la cour de Bourgogne.

34. T.-H. BORCHERT, «Le portrait de Charles le Téméraire ", in S. MARTI et alii, Charles le Téméraire..., op. cit., p. 72-81. Quant au noir des habits des princes, Philippe le Bon avait décrété le deuil pour l'assassinat de son père, mais la mode va s'assouplir un peu sous Charles.

35. On rappellera ici la fonction ducale symbolique de l'épée passée au Téméraire à la fin des obsèques de Philippe le Bon à Bruges en 1467 (w. PARAVICINI, «Le parchemin de Montpellier... », op. cit., p. 331), et, dans son convoi funéraire de Bruges à Dijon, l'épée présentée sur le cercueil, «le pommeau tourné devers le chief du duc» comme «vicair[e] perpetuel d'Empereur» (ID., «Theatre of Death. The Transfer of the Remnants of Philip the Good and Isabel of Portugal to Dijon, November 1473-February 1474 », in K. H. SPIESS et I. WARNTJES (éd.), Death at Court, Wiesbaden, 2012, p. 50-51 et 61). En 1469, Charles a fait réparer diverses armes d'apparat et de cérémonie par Gérard Loyet, dont l'épée de son père conservée à Vienne, avec son fourreau sculpté dans une dent de narval (voir l'article de H. TRNEK dans S. MARTI et alii, Charles le Téméraire..., op. cit., p. 280-281).

36. T.-H. BORCHERT, « Le portrait... », op. cit., p. 79.

37. R. PROCHNo, «Bildnisse Karls des Kühnen", in N.GRAMACCINI et M.C.sCHURR (éd.), Kunst und Kulturtransfer..., op. cit., p. 22-25. Pour les cheveux, la barbe temporaire sans moustache du Téméraire, voir W. PARAVICINI, « Le parchemin de Montpellier... », op. cit., p. 331. 
38. À l'avers : DUX.KAROLUS-BURGUNDUS, et au revers : JE L AI EMPRINS / BIEN EN AVIENGNE. S. MARTI et alii, Charles le Téméraire..., op. cit., p. 78, ill. 61 (Vienne, Kunsthistorisches Museum, Münzkabinett) et D. SCHMUTZ, "Giovanni Candida, un médailleur italien à la cour de Charles le Téméraire ", in S. MARTI et alii, Charles le Téméraire..., ibid., p. 224-229; w. PARAVICINI, Colleoni und Karl der Kühne, Berlin 2014, p. 97.

39. La bibliographie est évidemment considérable, signalons seulement : J. PAVIOT, Du nouveau sur l'ordre de la Toison d'or, en ligne [https://www.persee.fr/doc/ jds_0021-8103_2002_num_2_1_1657]; E. MIRA et A. DELVA (éd.), Toisón de Oro, Almudin, 2007 ; A. MARCHANDISSE et G. DOCQUIER (éd.), Autour de la Toison d'or. Ordres de chevalerie et confréries nobles aux $\mathrm{XIV} V^{e}-\mathrm{XVI} I^{e}$ siècles, Neuchâtel, 2019.

40. S. DÜNNEBEIL, «Der Orden vom Goldenen Vlies und die Beherrschung des Adels. Karl als Herr oder Ordensbruder ? ", in K. oscheMA et R. c. schwinges (éd.), Karl der Kühne..., op. cit., p. 171-183.

41. https://www.khm.at/objektdb/detail/100661/. Voir l'article de H. TRNEK dans S. MARTI et alii, Charles le Téméraire..., op. cit., p. 189 et F. KIRCHWEGER, Additionen, in S. MARTI et alii, Charles le Téméraire..., ibid., p. 90.

42. Catalogue de l'exposition Byzantium: Faith and Power (1261-1557), New York, Metropolitan Museum, 2004, p. 223 (A. EFFENBERGER) et W. PARAVICINI, «Montée, crise, réorientation. Pour une histoire de la famille de Croy au XV siècle ", Revue belge de philologie et d'histoire, 2020, $\mathrm{n}^{\circ} 4$, c. 22.

43. Les archives rapportent que Loyet a réalisé plusieurs colliers. Ils sont généralement faits de plusieurs pièces (seize pour celui de Vienne) avec les trois éléments, les deux briquets disposés en opposé et séparés par les flammes. Celui du reliquaire de Liège, minuscule, est une seule pièce coulée, qui a été refixée par-dessus l'armure avec deux vis modernes, ce qui a occasionné la perte de la partie arrière du collier.

44. C. BLAIR et M. CAMPBELL, "L'énigmatique offrande du Téméraire", Connaissance des arts, 349 (1981), p. 78-81.

45. Depuis plusieurs années, nous procédons, avec le restaurateur Louis-Pierre Baert, à une restitution réversible de l'œuvre pour cacher les neuf trous de fixation trop visibles et rendre à la pièce un peu plus encore de son lustre d'antan. Depuis longtemps, nous pensions qu'une reconstitution bien faite des « accessoires " manquants, dont se plaint déjà en 1867 le chanoine Thimister, serait la bienvenue. C'est la détérioration soudaine du coussin en 2007 qui a été le détonateur de toute cette entreprise. Depuis 2016, la modélisation 3D de l'œuvre nous suggère encore la possibilité d'autres initiatives, cf. M. GIL, «E-Thesaurus. Vers une économie numérique du patrimoine. E-corpus de l'orfèvrerie septentrionale, $\mathrm{XII}^{\mathrm{e}}-\mathrm{XIII}^{\mathrm{e}}$ siècles », p.16-19, en ligne [http://www.tresordeliege.be/publication/pdf/050.pdf]. Tous ces aspects de conservation, restauration et restitution de l'œuvre sont abordés en détail dans notre nouvel ouvrage sur le reliquaire, L'ymage d'or..., op. cit.

46. The J. Paul Getty Museum, Ms. 7, fol. 2, par Jean Fouquet (1455). C'est aussi, à notre avis, l'un des principaux intérêts du dessin aquarellé de l'armorial de Dijon (1584).

47. De plus, une vis moderne vient solidariser les deux statuettes : la main de saint Georges sur l'épaule du Téméraire.

48. F. DE VRIENDT, "Les interventions miraculeuses de saint Georges dans les batailles au Moyen Âge. Relevé et réflexions ", in M. BALLEZ, J.-L. DEPOTTE et B. KANABUS (éd.), Saint Georges et le dragon. Genèse et génération de récits, Louvain, 2018, p. 43-54, et ses contributions dans : B. KANABUS (éd.), La ducasse rituelle de Mons, Bruxelles, 2013 ; "Saint Georges et l'arbalète », Feuillets de la cathédrale de Liège, 2010 ; La gloire de saint Georges. L'homme, le dragon et la mort, catalogue d'exposition, Mons/ Grand Hornu, 2015.

49. Lors de sa mise en gage à Paris de 1483 à 1494 : P. GEORGE, « Le trésor des reliques de SaintLambert... ", op. cit., p. 71. 
50. C'est Pierre Colman le premier qui, en 1968 dans son guide du Trésor (éd. Le Vieux-Liège, p. 28, réédité en 1981), parle de «la prétention du duc d'être un nouveau saint Georges, miles christianus par excellence ». Saint Georges est aussi le patron de l'ordre de la Jarretière, conféré à Charles à la suite de son mariage avec Marguerite d'York. Loyet a réalisé un collier de la Jarretière en 1470 et des colliers de la Toison d'or.

51. M.-T. CARON et D. CLAUZEl (éd.), Le Banquet du Faisan. 1454 : l'Occident face au défi de l'Empire ottoman, Arras, 1997.

52. R. BACHA et L. BAVEYE, «Le mauvais côté de la croisade ? À propos d'un document établi par les chirurgiens de Philippe le Bon », Revue du Nord, 380/2 (2009), p. 491-510.

53. Jacques Paviot écrit: "La croisade, contre l'Infidèle ou l'hérétique hussite, a été un motif récurrent du règne de Philippe le Bon, qui en a fait deux fois le vœu, en 1451, lors du chapitre de l'ordre de la Toison d'or à Mons et, en 1454, publiquement et bien loin de la religion, lors du banquet du Faisan à Lille. Philippe et son fils Charles - ce dernier, notamment au chapitre de la Toison d'or à Valenciennes, en 1473 - se sont posés en champions de la foi chrétienne. Peut-on pour autant parler de pose vaine ? Je pense qu'il y avait plus de sincérité chez le père que chez le fils. D'autre part, le but politique est évident: acquérir renommée et se hausser au rang des rois", cf. en ligne [https://perspectivia.net//servlets/MCRFileNodeServlet/ ploneimport_derivate_00009560/paviot_etat.pdf].

54. C. BEAUFORT-SPONTIN et S. MARTI, "Armures italiennes d'apparat ", in S. MARTI et alii, Charles le Téméraire..., op. cit., p. 230-233.

55. Sur base des minutieuses descriptions des travaux d'orfèvre dans les comptes, on pourrait aussi supposer que la pièce était complétée de pierres précieuses qui ont disparu.

56. Par la mauvaise interprétation d'un document, Gérard Loyet a été considéré comme un orfèvre de Lille alors qu'il n'y a jamais travaillé. Après son décès en 1500, les Humbelot descendants du beau-père de Loyet s'implantent à Bruges comme maîtres de monnaies, voir N. CARTIER, Les orfèvres de Lille, Louvain, t. 1, 2005, p. 25.

57. http://vlaamseprimitieven.vlaamsekunstcollectie.be/nl/onderzoek/webpublicaties/ madonna-met-kanunnik-joris-van-der-paele. Orientation bibliographique dans P. CoLMAN, Jan van Eyck et Jean sans Pitié, Bruxelles, 2009, et p. 56, ainsi que p. 122-125 : notre recension dans la Revue d'histoire ecclésiastique, 2011, p. 264-267. Catalogue de l'exposition de Gand: M. MARTENS, T.-H. BORCHERT, J. DUMOLYN, J. DE SMET et F. VAN DAM (éd.), Van Eyck. Eine optische Revolution, Stuttgart, 2020, et https://www.academia.edu/42295382/The_Ghent_Altarpiece._A_Bibliography. Tous les artistes cités ci-dessous ont une notice détaillée dans notre ouvrage sur le reliquaire L'ymage d'or..., op.cit. , dont le sous-titre est Art et histoire au temps du Téméraire.

58. H. VAN DER VELDEN, The Donor'Image..., op. cit., p. 126-130. B. SCHERNB, « La croix de saint André ensaigne congnoissable des Bourguignons ", in M. AURELL et alii (éd.), Signes et couleurs des identités politiques du Moyen Âge à nos jours, Rennes, 2008, p. 45-55.

59. D. GABORIT-CHOPIN, "L'émaillerie gothique parisienne », Métiers d'art, 1978, p. 26-31; EAD., "Orfèvrerie et émaillerie ", in Les fastes du gothique, Paris, 1981, p. 220-234; C. ARMINJoN et M. BILIMOFF, «Émail sur ronde-bosse », L'art du métal, Paris, 1998, p. 208-211; R. EIKELMANN, «Les émaux sur ronde-bosse d'or ", in Paris 1400. Les arts sous Charles VI, Paris, 2004, p. 165-180 ; «Les émaux sur ronde-bosse d'or fabriqués à Paris autour de 1400 ", in I. BIRON, Émaux sur métal du IX ${ }^{e}$ au XIX siècle. Histoire, technique et matériaux, Dijon, 2016, p. 296-311.

60. Sur toutes ces œuvres, voir E. KovÀcs, L'âge d'or de l'orfêvrerie parisienne au temps des princes de Valois, Budapest, 2004.

61. É. TABURET-DELAHAYE, "L'orfèvrerie », in L'art à la cour de Bourgogne. Le mécénat de Philippe le Hardi et de Jean sans Peur (1364-1419), Dijon, 2004, p. 128 sqq.

62. Hugo Van der Velden esquisse une fort intéressante comparaison de valeur entre peinture et orfèvrerie à l'époque (p. 65-67). D'abord, c'est la valeur des matériaux utilisés qui est fortement 
estimée par rapport au coût du travail de l'artiste : les 1200 livres de la dépense de 1467 du reliquaire couvriraient seulement ceux-ci, alors qu'un artisan-orfèvre n'en gagnerait que 160 l'année. Ensuite, la peinture est dépréciée par rapport à l'orfèvrerie: à titre d'exemple, l'extraordinaire Jugement dernier de Memling estimé seulement à 600 livres (Gdańsk, 1467-1471).

63. R. EIKELMANN, «Les émaux... », op. cit., p. 174-177, nº 95 [http://archive.wikiwix.com/cache/? url=http\%3A\%2F\%2Fmini-site.louvre.fr\%2Fparis1400\%2Fparis1400\%2F01parcours-

expo\%2F05.html]; É. TABURET-DELAHAYE, «Parures et bijoux de la reine Isabeau de Bavière", Bulletin de la Société nationale des Antiquaires de France, 2008, p. 242-269, en ligne [https://doi.org/ 10.3406/bsnaf.2008.10611] ; J. STRATFORD, "The Goldenes Rössl and the French Royal Collection », in E. M. TYLER (éd.), Treasure in the Medieval West, York, 2000, p. 109-133 ; ID., Richard II and the English Royal Treasure, Rochester, 2013, p.63. J. HIRSCHBIEGEL, Étrennes. Untersuchungen zum höfischen Geschenkverkehr im spätmittelalterlichen Frankreich der Zeit König Karls VI, Munich, 2003, p. 62-65.

64. E. KovÀcs, "Rose. Les métamorphoses d'un motif ", in ID., L'âge d'or..., op. cit., p. 180-193. S. MARTI et alii, Charles le Téméraire..., op. cit., $\mathrm{n}^{\circ} 73$ (infra) et $\mathrm{n}^{\circ} 96$ (s. MARTI : « la rose blanche » du trésor du Téméraire). Gérard Loyet avait aussi créé de précieuses plumes pour le chapeau du duc, saisi comme butin par les Suisses. Nous en avons connaissance par une aquarelle (vers 1504) conservée au musée de Bâle ; la plume était faite de pierres précieuses (S. MARTI et alii, Charles le Téméraire..., ibid., p. 310-311).

65. Catalogue de Berne-Vienne-Bruges, $n^{\circ} 73$ p. 259-260 (H. VAN DER VELDEN). Marguerite aurait aussi offert un collier à la Vierge (B. FRANKE, Ibidem, $\mathrm{n}^{\circ} 75$ p. 261).

66. Loyet a été mis à contribution pour de l'argenterie armoriée pour le mariage.

67. Synthèse et bibliographie dans notre article « Flores Ecclesiae Leodiensis. Le culte des anciens saints liégeois au XVII ${ }^{\mathrm{e}}$ siècle », Subsidia hagiographica, t. 98, Bruxelles, 2020, p. 1-22.

68. A. MARCHANDISSE, «Jean de Heinsberg (1419-1455) ou le dilemme d'un prince-évêque de Liège écartelé par des options politiques antagonistes", Publications du Centre européen d'études bourguignonnes (XIV -XVI $I^{e}$ siècle), 38 (1998), p. 82.

69. M. BOONE, "Charles le Téméraire face au monde urbain: ennemis jurés et fatals?", in K. OSCHEMA et R. C. SCHWINGES (éd.), Karl der Kühne..., op. cit., p. 189. À Utrecht, Philippe le Bon était parvenu à faire installer son fils naturel David, et à Liège il choisit le nouvel évêque de Liège au sein de sa famille, en la personne de Louis de Bourbon, son neveu, le fils de sa sœur Agnès et du duc Charles de Bourbon. En novembre 1455, «au terme d'une procédure dont le duc de Bourgogne est l'incontestable maître d'œuvre ", Heinsberg renonce au siège épiscopal liégeois et sa démission est avalisée par le pape (A. MARCHANDISSE, «Jean de Heinsberg... », ibid., p. 83). Faut-il nuancer à la lecture de la riche bibliographie historiographique sur les bâtards? M. HARSGOR, «L'essor des bâtards nobles au XV siècle», Revue historique, 253 (1975), p. 319-354 ; N. BULST, «Illegitime Kinder - viele oder wenige?», in Illegitimität im Spätmittelalter, Munich, 1994, p. 21-40; M. CARLIER, Kinderen van de Minne? Bastaarden in het viftiende-eeuwse Vlaanderen", Bruxelles, 2001 ; c. AVIGNON (éd.), Bâtards et bâtardises dans l'Europe médiévale et moderne, Rennes, 2016 : il est des bâtardises à appréhender.

70. B. SCHNERB, « La piété de Charles le Téméraire », in G. ANNAS et J. NOWAK (éd.), Et l'homme dans tout cela... », op. cit., p. 669-684.

71. D. THoss, «Le Téméraire/Der Tollkühne - ein bibliophiler Mäzen?", in K. oschEMA et R. c. schwinges (éd.), Karl der Kühne..., op. cit., p. 222-233. "Passés les romans d'Arthur et les chroniques locales, il se fera lire des œuvres parlant de Cyrus le Jeune, d'Alexandre et de Jules César, des exemples de gloire et de pouvoir» (W. PARAVICINI dans S. MARTI et alii, Charles le Téméraire..., op. cit., p. 40).

72. A. VAUCHEZ, La sainteté en Occident aux derniers siècles du Moyen Âge, Rome, 1981.

73. A. RAPP BURI et M. STUCKY-SCHÜRER, Burgundische Tapisserien im Historischen Museum Bern, Munich, 2001. La tapisserie millefleurs provient du butin de Grandson. Les tapisseries de l'histoire de 
Trajan ou de César proviennent du Trésor de la cathédrale de Lausanne : la première appartenait à l'évêque de Lausanne Georges de Saluces (vers 1400-1461); la série sur César appartenait à Guillaume de la Beaume de Montrevel (vers 1430-1501), qui était à la cour de Charles le Téméraire. On ignore pourquoi Guillaume a fait cadeau de ces tapisseries à la cathédrale : est-ce à l'annonce du mariage de Maximilien d'Autriche et de Marie de Bourgogne en mai 1476 dans la cathédrale de Lausanne? Les Bernois ont saisi le trésor de la cathédrale en 1536 pendant les luttes de la Réforme : dès ce moment, toutes les tapisseries bourguignonnes sont à Berne.

74. B. Franke et P. Jezler dans S. MARTI et alii, Charles le Téméraire..., op. cit., p. 311-314: quatre tapisseries vers 1450-1470, où « les exploits de Jules César sont transposés dans l'univers de la culture courtoise et militaire bourguignonne».

75. B. FRANKE, "Le panthéon héroïque de Charles le Téméraire", in S. MARTI et alii, Charles le Téméraire..., ibid., p. 304-305.

76. N'est-ce pas aussi paradoxal qu'elles soient conservées en Suisse ? Comme à Liège, le reliquaire, l'une des plus belles représentations du duc, dans une ville qu'il a mise à sac... Ironie du destin.

77. W. PARAVICINI, "Folie raisonnante», op. cit., p. 41-45: un prince épris de justice, un prince bourreau de travail, un prince bureaucratique, un monarque absolu, un prince rigoriste, un prince moraliste, un prince parcimonieux, un prince fastueux, un prince cérémonieux, un prince ambitieux, un prince à cheval sur l'honneur, un prince bouillant, un prince cruel, un prince craint, un prince moderne.

78. H. VAN DER VELDEN, The Donor'Image..., op. cit., p. 155.

79. S. MARTI, "Représentations des donateurs et dons tardifs", in S. MARTI et alii, Charles le Téméraire..., op. cit., p. 249-251. Louis XI fait de même: répertoire étendu de ses offrandes et fondations dans W. PARAVICINI, "Sterben und Tod Ludwigs XI", in A. BORST, G. V. GRAEVENITZ et A. PATSCHOVSKY (éd.), Tod im Mittelalter, Constance, 1995 (1 ${ }^{\text {re }}$ éd. 1993), p. 77-168.

80. H. VAN DER VELDEN, The Donor'Image..., op. cit., p. 155.

81. En 1567, dans sa Description de tout le Païs-Bas, Guicchardin écrivait (en Italien) : « un S. George a cheval de fin or, qui luy fut donné par le Duc Charles de Bourgoigne pour repentance \& amende de soy mesme imposee, pour avoir tant cruellement traictee ceste noble Cité » (p. 373).

82. A. DE SCHRYVER, The Prayer Book of Charles the Bold, Los Angeles, 2008.

83. E. Morrison dans The Last Knight: The Art, Armor, and Ambition of Maximilian I, New York, catalogue d'exposition, 2019, p. 64-65.

84. C. GODEFROID, «L'avouerie de la cathédrale Saint-Lambert de Liège, dite avouerie de Hesbaye, du x $\mathrm{x}^{\mathrm{e}}$ au milieu du XIV ${ }^{\mathrm{e}}$ siècle », Le Moyen Âge, 81 (1975), p. 371-406 et J.-L. KUPPER, « L'avouerie de la cité de Liège au haut Moyen Âge ", Publications de la Section historique de l'Institut grand-ducal de Luxembourg, 98 (1984), p. 95-113.

85. Claude Gaier a bien montré qu'en cette fin du Moyen Âge le gonfanon remplace sur les champs de bataille les reliques de saint Lambert, qu'on y portait jadis pour stimuler l'enthousiasme des soldats. En 1141, 1151 et 1213 saint Lambert eut ses « triomphes ", c'est-à-dire que la victoire est attribuée à son intercession. C.GAIER, «Le rôle militaire des reliques et de l'étendard de saint Lambert dans la Principauté de Liège ", Le Moyen Âge, 72 (1966), p. 235-264. Synthèse dans C. GAIER et P. GEORGE, Liège. Autour de l'an mil, la naissance d'une principauté ( $\mathrm{X}^{e}-\mathrm{XII}{ }^{e}$ siècle), Liège, 2000, p. 72-78.

86. Voir références et commentaires dans H. VAN DER VELDEN, The Donor'Image..., op. cit., p. 94.

87. Notre ouvrage Reliques. Se connecter à l'au-delà, Paris, 2018. Sur le « riche » trésor de reliques du Téméraire, « qui les exhibait volontiers lors de grandes occasions », voir S. MARTI et alii, Charles le Téméraire..., op. cit., p. 282-284 (Y. LEHNHERR et H. WESTERMANN-ANGERHAUSEN).

88. J.-L. KUPPER, Liège et l'Église impériale, $X^{e}$-XII siècles, Paris/Liège, 1981, p. 523 sqq. Toutefois, l'expression elle-même ne se retrouve pas dans les textes. 
89. N'est-ce pas le même but que ces cités miniatures en argent, ces «villes d'argent ", comme Dieppe, Arques ou La Guerche en Bretagne donnée en 1471 par Louis XI « in remembrance of the fact that God has given me that city » (H. VAN DER VELDEN, The Donor'Image..., op. cit., p. 241-243) ?

90. On relèvera au passage les dons faits par le Téméraire aux lieux de culte sous le vocable de saint Georges (B. SCHNERB, «La piété... ", op. cit., p. 682). Hugo Van der Velden avait déjà relevé que Charles jurait per sanctum Georgium (d'après l'Historia de Théoderic Paul) et noté sa dévotion (especial reliance) envers saint Georges sur son itinéraire vers et au retour du sac de Liège (H. vAN DER VELDEN, The Donor'Image..., ibid., p. 127, 151 et 122-153), sans oublier son étendard à l'effigie du saint. Dès 1477, des messes sont commissionnées « devant l'image [de] monseigneur saint George lez Delf » (ibid., p. 199).

91. H.VAN DER VELDEN, The Donor'Image..., ibid., p.101-105. La légende de la photographie de l'Histoire de Belgique d'Henri Pirenne, édition posthume illustrée de 1962 (Bruxelles, t. 1), p. 409 : « en expiation de ses cruautés ».

92. La symbolique du pouvoir liégeois, au Moyen Âge tardif, est très largement liée à la personne du prince-évêque: A. MARCHANDISSE, La fonction épiscopale à Liège aux XIII et XIVe siècles. Étude de politologie historique, Genève, 1998, p. 275-306.

93. Le conditionnel, que nous employons, nous est tout personnel dans l'hypothèse ci-dessous pour le reliquaire. J. BARTIER, « Un discours du chancelier Hugonet aux États Généraux de 1473 », Bulletin de la Commission royale d'histoire, 57 (1942), p.127-156: «Et, comme nul de sain entendement ne puist ces choses nyer ou ignorer, il convient que les intencions, entendemens et affections de saige prince et de bons subgetz soient tellement conjoinctes et connexees que le prince ne extime ou repute auchune chose lui estre plus prochaine, lui plus appartenir, que le commun bien de la chose publicque et des subgetz a lui submis, et que les subgetz n'entendent ou n'extiment aucune chose estre particuliere au prince, soit décroissance ou d'amendissement d'honneur, d'auctorité, de seignourie et puissance qui ne soit également commune aux subgetz et a la chose publicque comme au prince (p. 139). " Évidemment, ce long discours est à replacer dans son contexte : obtenir des États généraux de l'argent pour faire la guerre. «A nostre chose publicque, qui est la généralité d'entre vous comprinse es trois estas que vous représentés, la guerre et le dangier d'icelle, comme a esté demonstré, touche plus que a nostre tres redoubté seigneur et toutesfoiz tous les pays ensemble n'y ont point tant mis a moitié, comme il a fait, combien que selon nature, pareille proporcion doive estre des commoditez et des cherges (p. 151).»

94. Voir J. DUMONT, en ligne [http://www.tresordeliege.be/publication/pdf/047.pdf], p. 3-7 et ID., «Conserver ou transformer les structures sociales? La place de l'idéologie ternaire au sein de la pensée politique française et bourguignonne à la fin du Moyen Âge ", in M. MARTIN (éd.), Les États : ordres, institutions et formes (France, 1302-1614), Paris, 2013, p. 43-71.

95. M. DEPRETER, «Moult cruaultéz et inhumanitéz y furent faictes. Stratégie, justice et propagande de guerre sous Charles de Bourgogne (1465-1477)», Le Moyen Âge, 121 (2015), p. 41-69, ici p. 46. Dans le développement de ce "discours musclé", l'auteur emploie aussi le terme de « message », qu'il qualifie de limpide pour son propos. Voir aussi P. CONTAMINE, « L'armée de Charles le Téméraire : expression d'un État en devenir ou instrument d'un conquérant ? ", in M. VAïsSE (éd.), Aux armes, citoyens !, Paris, 1998, p. 61-77. Le même terme (« message ») est utilisé par W. Paravicini («Le parchemin de Montpellier... », op. cit., p. 337) : le prince assure la paix et la justice comme programme de gouvernement.

96. M. DEPRETER, « Moult cruaultéz », ibid., p. 47.

97. M. DEPRETER, « Moult cruaultéz », ibid., p. 68.

98. J. BARTIER, Charles le Téméraire, Bruxelles, $2^{\mathrm{e}}$ éd., 1970, p. 98.

99. Le chroniqueur Jean de Stavelot avait déjà présenté l'assassinat de Jean sans Peur à Montereau en 1419 comme la revanche de saint Lambert sur le vainqueur d'Othée en 1408 (JEAN 
DE STAVELOT, Chronique, éd. A. BORGNET, Bruxelles, 1861, p. 169). Sur les sentiments antibrabançons à Liège, voir A. MARCHANDISSE, "Jean de Heinsberg... ", op. cit., p. 85-86. L'expression est de Patrick Fers, consul général de France à Liège, dans son introduction à notre ouvrage J.-L. KUPPER et $P$. GEORGE, Charles le Téméraire, op. cit., p. 9-10.

100. Pour Liège, au XIX ${ }^{\mathrm{e}}$ siècle, la période est l'un des rares épisodes internationalement connus de son histoire. Si les chroniqueurs s'étaient «émerveillés » du carnage que fut le sac de Liège, c'est Walter Scott qui le fait connaître dans son Quentin Durward, prolongé par le cinéma: le romantisme et ses héritiers en ont, de la sorte, amplifié le souvenir.

101. Georges Chastellain d'après B. SCHNERB, « La piété... », op. cit., p. 671.

102. H. VAN DER VELDEN, The Donor'Image..., op. cit., p. 97.

103. Y. CHARLIER, "La bataille d'Othée et sa place dans l'histoire de la principauté de Liège ", Bulletin de l'Institut archéologique liégeois, 97 (1985), p. 246-248. Sur ce prélat hors du commun, voir A. MARCHANDISSE, «L'entourage de Jean de Bavière, prince-élu de Liège (1389-1418) », in J.-L. KUPPER et A. MARCHANDISSE (éd.), À l'ombre du Pouvoir. Les entourages princiers au Moyen Âge, Liège, 2003, en ligne [http://books.openedition.org/pulg/5628].

104. É. LECUPPRE-DESJARDINS, La ville des cérémonies. Essai sur la communication politique dans les anciens Pays-Bas bourguignons, Turnhout, 2004. On y ajoutera l'influence de ce facteur d'unité qu'est la monnaie frappée dans les Pays-Bas bourguignons dès 1433, dont celle à l'effigie du duc qui popularise les traits de son visage, comme sur le reliquaire en nouveau chevalier du Christ.

105. F. JOUBERT, «Le mariage de Charles le Téméraire et Marguerite d'York et ses implications artistiques », in N. GRAMACCINI et M. C. SCHURR (éd.), Kunst und Kulturtransfer..., op. cit., p. 113.

\section{RÉSUMÉS}

Le reliquaire dit de Charles le Téméraire (or, argent et émaux, h. $53 \mathrm{~cm}$ et poids total $5 \mathrm{~kg}$ ), œuvre majeure du patrimoine national belge, a été réalisé entre 1467 et 1471 par l'orfèvre Gérard Loyet. Depuis les dernières importantes publications (2000-2012), des éléments neufs sont encore apparus dans le dossier. Nous formulons ici quelques hypothèses inédites dans la lecture de ce groupe orfévré, qui a été restauré et vient d'être mis définitivement en place au Trésor de la Cathédrale de Liège.

The reliquary known as Charles the Bold's reliquiary (gold, silver and enamel, h. $53 \mathrm{~cm}$, overall weight c. $5 \mathrm{~kg}$ ), a major work of Belgian national heritage, was produced between 1467 and 1471 by the goldsmith Gérard Loyet. Since the last major publications (2000-2012), new elements have still appeared in the dossier. We formulate here some unpublished hypotheses in the reading of this goldsmith group which has been restored and has just been definitively put in place at the Liège Cathedral Treasury. 
INDEX

Keywords : Duke of Burgundy, Charles the Bold, Gérard Loyet, Goldsmithery, Enamelware, Liège, Relics

Mots-clés : duc de Bourgogne, Charles le Téméraire, Gérard Loyet, orfèvrerie, émaillerie, Liège, reliques

\section{AUTEUR}

PHILIPPE GEORGE

Conservateur honoraire du Trésor de la Cathédrale de Liège 